\title{
Successful multiple Percutaneous Interventions and Biventricular Surgical Repair in a Child with Pulmonary Atresia with Intact Ventricular Septum-A Case Report
}

\author{
Nurun Nahar Fatema Begum, Md Ferdousur Rahman Sarkar, Md Ashfaque Ahemmed Khan, \\ Mohammad Nazmul Islam Bhuiyan \\ Department of Paediatric Cardiology, CMH Dhaka
}

\begin{abstract}
:
Key Words :

Percutaneous

intravenous,

Pulmonary

atresia,

Periventricular

Pulmonary atresia (PA) with intact ventricular septum is a rare, heterogeneous congenital heart defect with varying degrees of right ventricular and tricuspid valve hypoplasia and wide spectrum clinical features. Initial treatment at presentation is to establish systemic to pulmonary shunt or ductus stenting. The treatment options i.e. biventricular, one and half ventricular or one ventricular repair are often dictated by the degree of development of the tricuspid valve and right ventricle. X, 11 years old teenage girl got admitted to Combined Military Hospital (CMH) Dhaka at 5 months of age with severe cyanosis, respiratory distress, acidosis and shock. After immediate stabilization and work up, she was diagnosed as pulmonary atresia with intact ventricular septum, flapped atrial septal defect $(A S D)$ and a small patent ductus arteriosus (PDA). On urgent basis, stenting of PDA done with $3.5 \times 11 \mathrm{~mm}$ coronary stent at cardiac catheterization laboratory. Her $\mathrm{SPO}_{2}$ stepped up to $90 \%$ from base line $\mathrm{SPO}_{2}$ from $50 \%$ following procedure. At 15 months of age she underwent intracardiac repair with short trans annular patch and ASD left open as a vent for $R V$. On follow up her ASD was getting larger and became desaturated and symptomatic. She was followed up for the right ventricular $(R V)$ and tricuspid valve growth and ASD shunt. As her $R V$ was developing nicely during follow up and achieved TV $z$ score -1, ASD device closure was done with $18 \mathrm{~mm}$ Amplatzer ASD device at 5 years of age. She is now asymptomatic and thriving well.
\end{abstract}

(Cardiovasc. j. 2020; 13(1): 81-85)

\section{Introduction:}

Pulmonary atresia with intact ventricular septum (PA IVS) is a disease with remarkable morphologic variability, affecting not only the pulmonary valve but also the tricuspid valve, the RV cavity and coronary arteries. ${ }^{1}$ Pulmonary atresia with intact ventricular septum is an uncommon condition associated with varying degrees of right ventricular hypoplasia with $1 \%$ incidence among patients with congenital heart disease (CHD). Pulmonary atresia with intact ventricular septum has generally been a difficult problem to manage. ${ }^{2}$ Children with this disease suffer from severe cyanosis that results in a high mortality rate without intervention or treatment. ${ }^{3}$ It is truly a complex, diverse disorder that challenges surgical and catheter-based interventional strategies that ranging from achieving a biventricular circulation to variations of the cavopulmonary circulation (Fontan operation or 1.5-ventricle repair) even up to cardiac transplantation. ${ }^{4}$

\section{Case history:}

$\mathrm{X}$, 11years old teenage girl had history of bluish discolouration of lips, tongue, finger tips, fast breathing in her neonatal period. Later at 5 months of age on 14 September 2009 she was admitted to Combined Military Hospital (CMH) Dhaka with cough for one month and cyanosis. At the time of admission she, weighing $4.5 \mathrm{~kg}$, was

Address of Correspondence: Brig. Gen. Nurun Nahar Fatema Begum, Department of Paediatrics and Paediatric Cardiology, CMH Dhaka, Bangladesh. E mail:colfatema@hotmail.com

- 2020 authors; licensed and published by International Society of Cardiovascular Ultrasound, Bangladesh Chapter and Bangladesh Society of Geriatric Cardiology. This is an Open Access article distributed under the terms of the CC BY NC 4.0 (https://creativecommons.org/licenses/by-nc/4.0) 

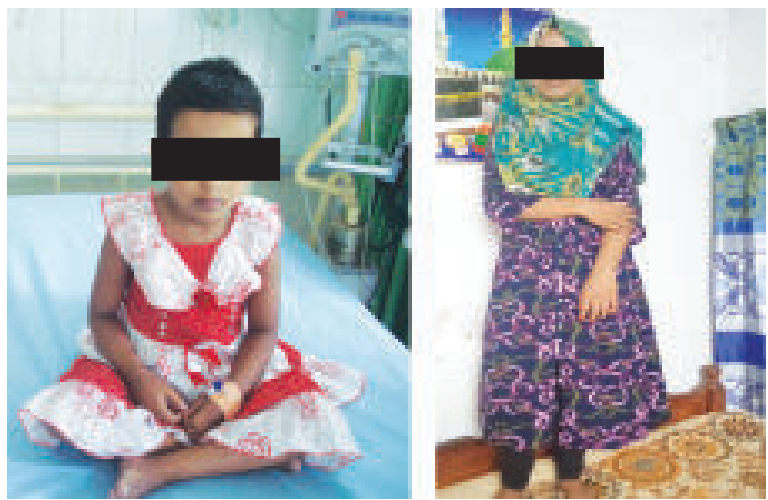

Fig.-1: Patient $X$ at 3 years and 11 years of age.

extremely dyspnoeic with oxygen saturation around $50 \%$. A soft pansystolic murmur was audible at the left lower sternal border. Her X-ray showed cardiomegaly with enlarged right atrium and oligemic lung. ECG showed normal sinus rhythm, right atrial enlargement and LV dominance. Echocardiography revealed situs solitus, levocardia, D-loop ventricles, membranous pulmonary atresia with intact inter ventricular septum, moderate flapped ASD with right to left shunt, small restrictive PDA of $1.5 \mathrm{~mm}$. RV was tripartite, muscle bound with borderline cavity size. Moderate to severe TR with dysplastic TV leaflets, hypoplastic MPA and hypoplastic confluent branch PAs, normal coronaries were noted. Arterial gas analysis showed metabolic acidosis. Considering very low oxygen saturation after stabilization, she was taken to the catheterization laboratory of $\mathrm{CMH}$ Dhaka on the next day of admission for urgent PDA stenting as an alternative to BT shunt considering hypoplastic PAs. Diagnostic angiogram confirmed echocardiographic findings. Her aortogram showed a tiny PDA with constriction at $\mathrm{PA}$ end. Then PDA stenting was done with $3.5 \mathrm{X}$ $11 \mathrm{~mm}$ Gazelle ${ }^{\circledast}$ coronary stent. Post stent injection showed good flow through the PDA and branch PAs. Immediately after stenting of the PDA her SPO2 stepped up to $90 \%$.

The child remained stable for 8 months after stenting of PDA. On routine follow up at 13 months of age she was found dyspnoeic and cyanosed with $\mathrm{SPO}_{2}$ $75 \%$. Then she was referred to surgeons for single/ biventricular repair which ever was suitable with the background of TV z score-2.6. Cardiac surgeon performed biventricular repair at 1 yr 3 months on 27 August 2010 i.e. resection of right ventricle muscle bundles with short trans annular patch and left ASD open as a vent for RV. PDA stent was explanted. Post repair aortic pressure was - 65/33 $\mathrm{mm} \mathrm{Hg}, \mathrm{RV}$ pressure - $42 / 6 \mathrm{~mm} \mathrm{Hg}$. Her post operative and subsequent follow up echocardiography showed borderline RV cavity with good RV function, moderate TR, ASD shunting right to left and the shunt size was getting larger, moderate PR, good sized confluent branch PAs.

After the surgery the child was reasonably well for about 30 months. Later it was observed that she was desaturating and dyspnoeic Class II NYHA and clubbing was present. Considering the right to left shunt through the enlarging ASD; she was taken to cardiac catheterization lab on 27 December 2012 at 3.8 years of age for assessing the possibility of closure of ASD. RV pressure was $26 / 0-8 \mathrm{~mm} \mathrm{Hg}$. ASD was occluded with $12 \mathrm{~mm}$ Tyshak II balloon for 30 minutes but the patient became haemodynamically unstable and the procedure was postponed.

At this point of time it was decided that the child will be followed up with $\mathrm{Hb}$ percentage, $\mathrm{PCV}$ and $\mathrm{SpO} 2$ check at 3 monthly intervals. But her RV was developing nicely during follow up and achieved TV $\mathrm{z}$ score -1 . So, the child was taken to cardiac catheterization laboratory for ASD device closure on 05 April 2014 at 5 years of age. RV pressure was normal. Balloon occlusion trial for 15 minutes was successful. So, we decided to close the ASD with 18 mm Amplatzer ${ }^{\circledast}$ septal occluder. Following ASD device closure her saturation stepped up to $98 \%$ without oxygen. Echocardiography also revealed good RV function with good antegrade flow through MPA.

\section{Procedure:}

Patent Ductus Arteriosus Stenting:

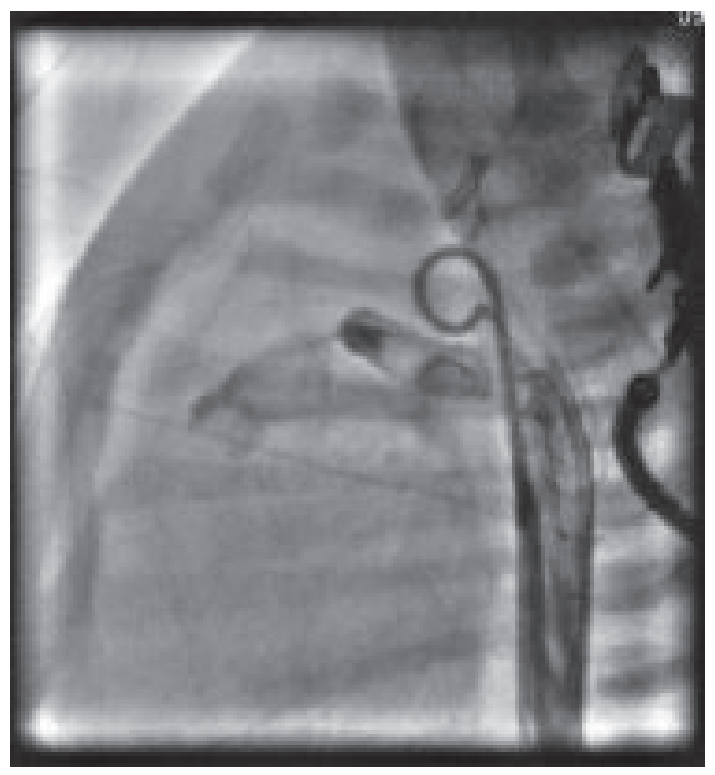

Fig-2: Aortogram showing small PDA 


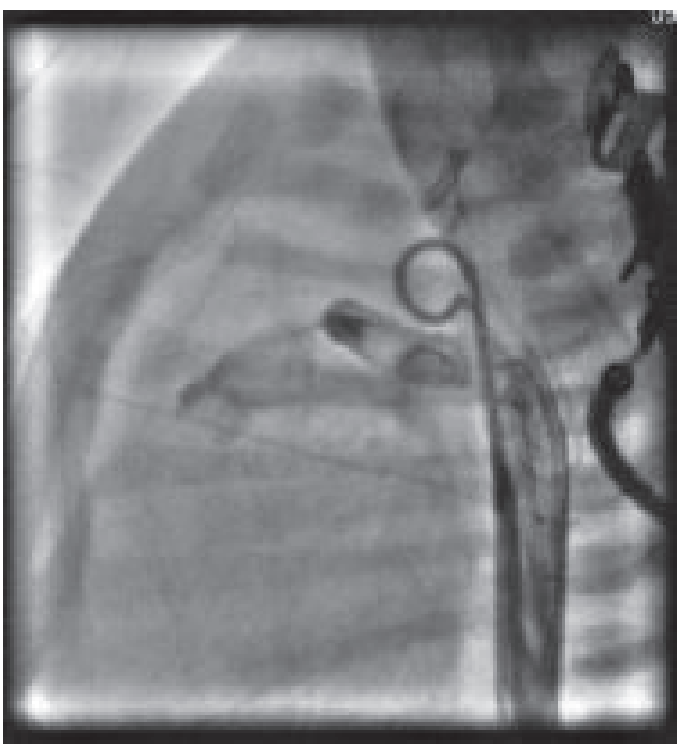

Fig-3: Showing stent inside the PDA.

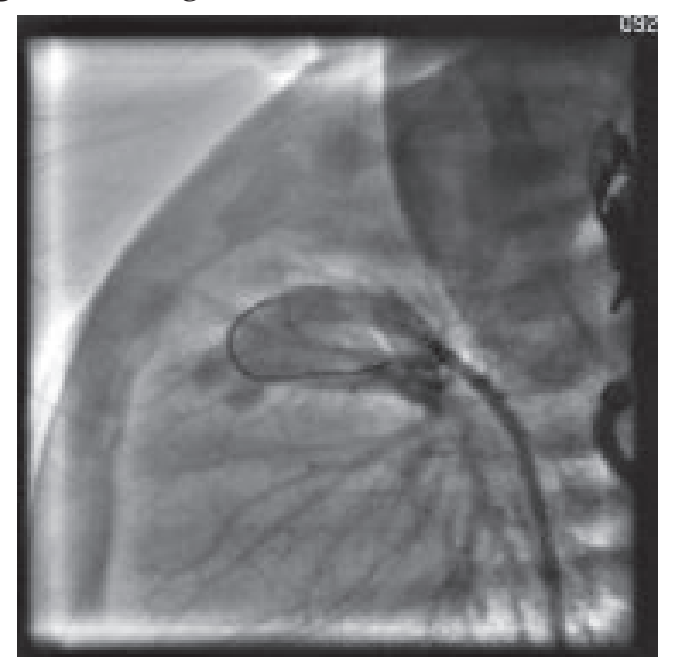

Fig-4: Showing good flow through stented PDA.

\section{ASD Device closure:}

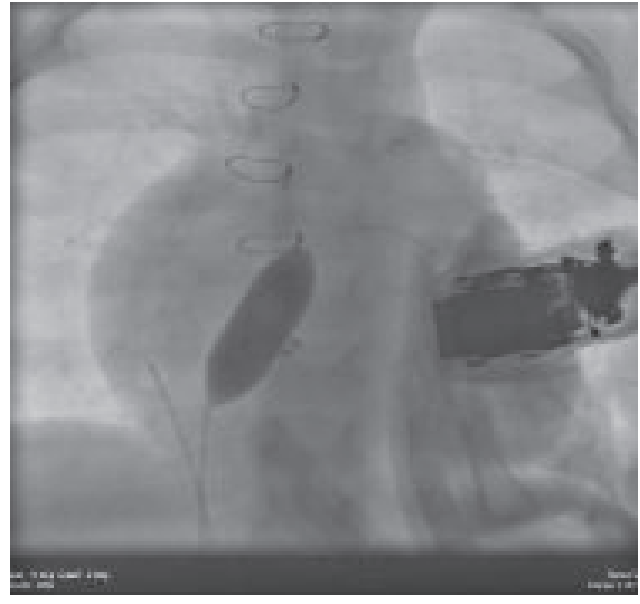

Fig-5: Balloon occlusion of ASD.

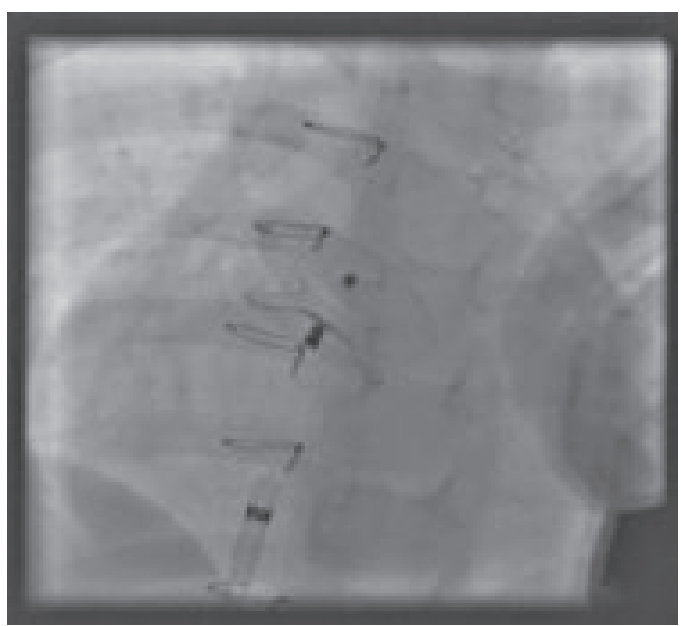

Fig-6: ASD device just released from device delivery cable.

\section{Discussion:}

The morphologic heterogeneity in Pulmonary atresia with intact interventricular septum encompasses a spectrum of lesions including some form of hypoplasia of the right ventricle (RV) and the tricuspid valve, abnormal coronary circulation, and pulmonary atresia itself. ${ }^{5}$ Management strategies therefore need tailoring to individual morphologic subtypes at presentation. ${ }^{3}$ The goals of treatment for PA-IVS are to eliminate cyanosis without compromising cardiac output and without inducing excessive systemic venous hypertension. ${ }^{6}$ Surgical and other catheter-based interventional therapies have continued to change with an understanding of the heterogeneity of this disorder. The diagnostic and therapeutic algorithms are now quite diverse, depending on a wide number of morphologic variables. ${ }^{7}$ If untreated, PA-IVS is a uniformly fatal form of structural cardiac disease. ${ }^{8}$ The treatment at presentation in the early life is patent ductus arteriosus (PDA) stenting, balloon atrial septostomy or conventional modified Blalock Taussig (BT) shunt. ${ }^{1}$ Our patient presented with severe hypoxaemia, acidosis and shock. Immediate surgical intervention was not feasible with her physical condition and surgeons refused also to do BT shut in this child. So, we took the decision for PDA stenting considering hypoplastic PAs, the physical condition and benefit of PDA stenting over BT shunt. Distortion of the branch pulmonary arteries, which is a disadvantage of aortopulmonary shunting by comparison with stent placement, has been 
observed in some patients. The implantation of stents for PDA appears to be an alternative to palliative surgery in patients with duct dependent pulmonary circulation. ${ }^{9,10}$ A study was conducted in Istanbul, Turkey where efficacy and safety of stent implantation in to the ductus arteriosus in infants with cyanotic heart disease was studied. Coronary stent was implanted in eight out of ten cases. All of them had adequate relief of cyanosis and was discharged home. This study recommends stenting as an effective alternative of surgical systemic pulmonary artery shunt. ${ }^{11}$

Several authors reported that the z-value of the tricuspid valve diameter could be a guide to take decision for surgical procedure; however, poor interobserver reproducibility and wide normal ranges are serious limitations. ${ }^{12}$ Using a cut off for the z-score of the tricuspid valve of more than -3 is useful predictor for successful biventricular repair. ${ }^{13}$ The most important problem when planning a strategy for a definitive repair is the fact that right ventricular growth and its contribution to pulmonary flow is difficult to predict before the operation. Bull and colleagues have proposed the tripartite classification of the RV and the size of the tricuspid valve as determinants of RV growth. ${ }^{14}$ Biventricular repair (BVR) may offer superior long-term outcome in patients with pulmonary atresia and intact ventricular septum (PA-IVS). ${ }^{15}$

Ideally, surgery should optimize growth of the RV and the tricuspid valve without compromising the coronary circulation and ventricular function. If all measures are favorable, a 2-ventricle repair will be achieved; if not, a 1- or 1.5-ventricle repair will be done. In recent years, attempting the biventricular pathway or biventricular conversions in patients with borderline ventricle has become a hot topic. However, inappropriate pursuit of biventricular repair in borderline candidates will lead to adverse clinical outcomes. Therefore, it is important to accurately assess the degree of ventricular development before operation and whether it can tolerate biventricular repair. ${ }^{16}$ Later observing the RV development catheter based interventions viz. repeat balloon dilatation or device closure of patent foramen ovale (PFO) may also be required in some patients. ${ }^{1}$ Jinghao Zheng et al. observed survival rates of 93.7 and
$88.2 \%$ as mid-term outcomes in the one-stage surgery group with PA/IVS. ${ }^{17}$

Our patient is now 11 years old and having no dyspnoea or desaturation. She is thriving well. The case history of this child is unique one considering her complex cardiac morphology with hypoplastic RV cavity. Usually patient with intact IVS ends up with single ventricle circulation. Staged intervention along with corrective surgery leads her to a normal physiological biventricular heart with two separate circulations. We will follow up the child to observe the function and size of the $R V$ cavity as well as any progress of $P R$ and TR.

\section{Conclusion:}

Pulmonary atresia with intact ventricular septum is difficult to manage but technological advances now permit the treatment of both relatively simple and very complex anatomical and pathophysiological problems using percutaneous techniques and surgical intervention. However these interventions require the operator to have expertise in congenital heart disease. Survival of pediatric patients after surgery for CHD has consistently improved over the past 2 decades. Timely decision with wisdom and experience for intervention along with long term follow up is critical for better outcome and survival.

\section{Conflict of Interest - None.}

\section{References}

1. Alwi M. Management algorithm in pulmonary atresia with intact ventricular septum. Catheter Cardiovasc Interv 2006; 67(5):679-686.

2. Leung MP, Mok C, Lee J, Lo RNS, Cheung H, Chiu C. Management evolution of pulmonary atresia and intact ventricular septum. Am J Cardiol 1993; 71: 1331-1336.

3. Ashburn DA, Blackstone EH, Wells WJ, et al. Determinants of mortality and type of repair in neonates with pulmonary atresia and intact ventricular septum. $J$ Thorac Cardiovasc Surg 2004; 127(4): 1000-1008.

4. Allen, Hugh D, Forrest H. Adams, and Arthur J. Moss. Moss and Adams' Heart Disease in Infants, Children, and Adolescents: Including the Fetus and Young Adult. $8^{\mathrm{TH}}$ ed. Philadelphia, PA: Lippincott Williams and Wilkins; 2007. 939p.

5. Zuberbuhler JR, Anderson RH. Morphological variations in pulmonary atresia with intact ventricular septum. $\mathrm{Br}$ Heart J 1979;41(3):281-288.

6. Jahangiri M, Zurakowski D, Bichell D, Mayer JE, del Nido PJ, Jonas RA. Improved results with selective 
management in pulmonary atresia with intact ventricular septum. J Thorac Cardiovasc Surg 1999;118(6):1046-1055.

7. Hanley FL, Sade RM, Blackstone EH, Kirklin JW, Freedom RM, Nanda NC. Outcomes in neonatal pulmonary atresia with intact ventricular septum. A multiinstitutional study. J Thorac Cardiovasc Surg 1993;105(3):406-424.

8. David MA, Stephen JR. Pulmonary atresia with intact ventricular septum (PA/IVS). Post TW, ed. Up To Date Waltham, MA: UpToDate Inc. https:// www.uptodate.com (Accessed on September 06, 2020.)

9. Schneider M, Zartner P, Sidiropoulos A, Konertz W, Hausdorf G. Stent implantation of the arterial duct in newborns with duct-dependent circulation. Eur Heart $J$ 1998;19(9): 1401-1409.

10. Odemis E, Haydin S, Guzeltas A, Ozyilmaz I, Bilici M, Bakir I. Stent implantation in the arterial duct of the newborn with duct-dependent pulmonary circulation: single centre experience from Turkey. Eur $J$ Cardiothorac Surg 2012;42(1):57-60.

11. Celebi A, Yalçin Y, Erdem A, Zeybek C, Akdeniz C, Polat TB. Stent implantation into the patent ductus arteriosus in cyanotic congenital heart disease with ductdependent or diminished pulmonary circulation. Turk J Pediatr. 2007;49(4): 413-417.
12. Yoshimura N, Yamaguchi M. Surgical strategy for pulmonary atresia with intact ventricular septum: initial management and definitive surgery. Gen Thorac Cardiovasc Surg 2009;57(7):338-346.

13. Silverman N.H. (2009) Imaging the Hypoplastic Right Heart - How Small Is Too Small?. In: Redington AN, Van Arsdell GS, Anderson RH, editors. Congenital Diseases in the Right Heart.1 ${ }^{\text {st }}$ ed. London. Springer;2009. 149-150.

14. Bull C, de Leval MR, Mercanti C, Macartney FJ, Anderson RH. Pulmonary atresia and intact ventricular septum: a revised Classification. Circulation 1982;66(2):266-272.

15. Karamlou T, Poynter JA, Walters HL 3rd, et al. Longterm functional health status and exercise test variables for patients with pulmonary atresia with intact ventricular septum: a Congenital Heart Surgeons Society study. J Thorac Cardiovasc Surg 2013;145(4):1018-1027.

16. Ma XJ, Huang GY. Prediction of biventricular repair by echocardiography in borderline ventricle. Chin Med $J$ (Engl) 2019;132(17):2105-2108.

17. Zheng J, Gao B, Zhu Z, et al. Surgical results for pulmonary atresia with intact ventricular septum: a single-centre 15-year experience and medium-term follow-up. Eur J Cardiothorac Surg 2016;50(6): 10831088. 